
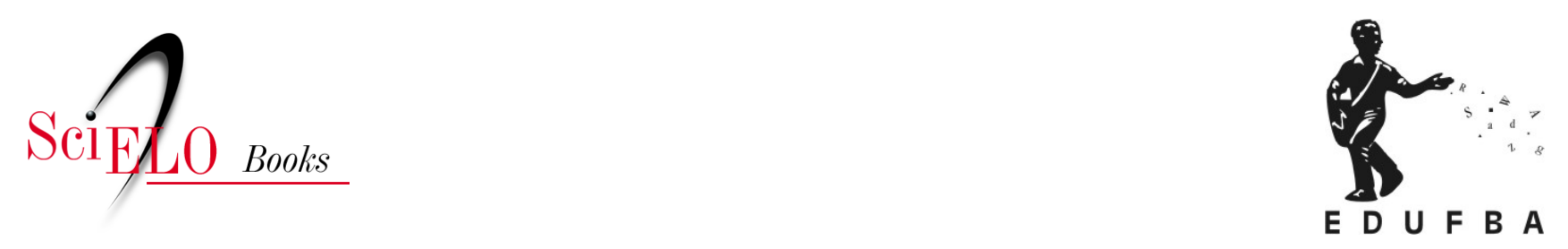

\title{
Tema 2 - Whatsapp e processos educativos Whatsapp: cenário para discussões e reflexões sobre a permissividade e limite da interação de crianças e adolescentes com o universo digital
}

\author{
Lynn Alves \\ Velda Torres
}

\section{SciELO Books / SciELO Livros / SciELO Libros}

ALVES, L., and TORRES, V. Whatsapp: cenário para discussões e reflexões sobre a permissividade e limite da interação de crianças e adolescentes com o universo digital. In: PORTO, C., OLIVEIRA, K.E., and CHAGAS, A., comp. Whatsapp e educação: entre mensagens, imagens e sons [online]. Salvador: Ilhéus: EDUFBA; EDITUS, 2017, pp. 169-191. ISBN 978-85-232-2020-4.

https://doi.org/10.7476/9788523220204.0010.

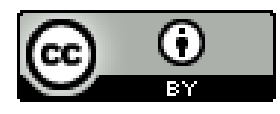

All the contents of this work, except where otherwise noted, is licensed under a Creative Commons Attribution 4.0 International license.

Todo o conteúdo deste trabalho, exceto quando houver ressalva, é publicado sob a licença Creative Commons Atribição $\underline{4.0}$. 


\title{
WHATSAPP: CENÁRIO PARA DISCUSSÓES E REFLEXÓES SOBRE \\ A PERMISSIVIDADE E LIMITE \\ DA INTERAÇÃO DE CRIANÇAS E ADOLESCENTES COM O UNIVERSO DIGITAL
}

\author{
Lynn Alves - UNEB e Centro Universitário SENAI - CIMATEC \\ Velda Torres - UFBA e UCSAL
}

\section{Introdução}

Os artefatos sociotécnicos contemporâneos aqui compreendidos como produçôes tecnológicas criadas dentro de uma sociedade que atende e cria novas demandas e necessidades no cotidiano da vida humana, vêm provocando mudanças na forma das pessoas se organizarem, acessarem informaçóes e produzirem novos conhecimentos.

Nesse contexto, destacamos a interface comunicacional WhatsApp, criada em 2009, por Jan Koum e Brian Acton e que em janeiro de 2017 já tinha 1,200 milhão ativo em nível global (JASON, 2017). Este software de comunicação que tem a origem do seu nome a partir do trocadilho inglês "What's Up" vem sendo usado por mais de 180 países e desde 2014 foi comprado pelo Facebook e está disponível gratuito para as plataformas IOS, Android, Windows e Windows Phone, BlackBerry e Nokia e também para computadores (SIMPLES..., 2017). 
Em 7 de junho de 2017 (às 23h30), foi exibida pela GloboNews uma entrevista com Brian Acton que esteve no Brasil para responder aos questionamentos do Supremo Tribunal Federal sobre o acesso aos dados de determinados usuários do Whats $A p p$ que realizam atividades criminosas. Durante a entrevista realizada por $\mathrm{Mu}-$ rilo Salviano, Acton declarou que o Brasil é o segundo maior mercado que utiliza este software de comunicação, tendo 120 milhóes de usuários, mais da metade da população do nosso país, estando atrás apenas da Índia. Segundo Acton, as mensagens são criptografadas e apenas quem envia e recebe a mensagem tem acesso ao teor das informaçóes enviadas, pois a empresa protege e preserva a privacidade dos usuários.

Essa polêmica que vem desde 2015 colocando o WhatsApp na mira da justiça ainda não chegou ao fim, mas constatamos a cada dia que esta mídia mudou a forma das pessoas utilizarem seus telefones móveis, especialmente os smartphones ${ }^{1}$. Maquininhas que atuam hoje como computadores na palma da mão e nos quais acessamos nossos arquivos nas nuvens computacionais, gerenciamos nossos e-mails e processos comunicacionais. Pessoas de distintas faixas etárias e níveis socioeconômicos e culturais interagem com seus smartphones e interfaces como o Facebook, messeger e o WhatsApp.

No relatório Growing Up Online - What kids conceal (2016), da Kaspersky Lab, publicado em 2016, relativo à pesquisa realizada nos Estados Unidos, França, Rússia, Itália, Espanha, Inglaterra e Alemanha, com 3.780 famílias, tendo como sujeitos uma criança e um pai por família, utilizando um instrumento on-line, foi constatado que $33 \%$ das crianças e adolescentes entrevistados, na faixa etária de 8 a 16 anos, utilizam mensagens instantâneas como WhatsApp.

1 A diferença básica entre um celular e um smartphone refere-se à capacidade multitarefa do segundo que além de ser multimídia permite o acesso a internet, redes sociais e também baixar aplicativos, jogar, entre outras possibilidades. Contudo, neste artigo estaremos utilizando os termos como sinônimos por conta das falas dos pais que foram sujeitos da pesquisa aqui apresentada. 
Deste percentual, 32\% são meninos e 38\% são meninas. Na Tabela abaixo, percebemos que as crianças que estão nas séries iniciais são as que mais utilizam, indicando que cada vez mais precocemente estes sujeitos interagem com este universo digital.

Usuários de WhatsApp

\begin{tabular}{|c|c|c|}
\hline $8-10$ anos & $11-13$ anos & $14-16$ anos \\
\hline $49 \%$ & $43 \%$ & $39 \%$ \\
\hline
\end{tabular}

Fonte: Adaptado de Growing Up Online (2016).

Estes dados também podem ser constatados no Relatório Adolescentes, Pré-adolescentes e Tecnologia (Teens, Tweens and Technology Report) (McAFEE, 2015), pesquisa que envolveu crianças e adolescentes australianos na faixa etária de 8 a 17 anos indicou que estes sujeitos quando estão na internet utilizam sites de relacionamento, a exemplo do Facebook (93\%), YouTube (87\%) e WhatsApp (79\%). Novamente percebemos que apesar de existirem restriçóes etárias de uso, elas não são respeitadas.

E por fim, o relatório do Centro Regional de Estudos para o Desenvolvimento da Sociedade da Informação (Cetic.br), publicado em 2017 pelo Comitê Gestor da Internet, indica que crianças de 9 a 10 anos declaram utilizar o Facebook (50\%) e WhatsApp (47\%) e em contraponto, os adolescentes na faixa etária de 15 a 17 anos registraram que possuem conta no Facebook (92\%) e WhatsApp (82\%), do total de 3.068 dos entrevistados no território brasileiro, quando estão na internet, enviam mensagens instantâneas. $\mathrm{E}$ quem são esses sujeitos? 


\section{Crianças e adolescentes na internet}

PROPORÇAO DE CRIANÇAS E ADOLESCENTTES QUE ACESSARAM A INTERNET NOS ÚLTIMOS TRĒS MESES (2015) Percentual sobre o total de crianças e adolescentes de 9 a 17 anos

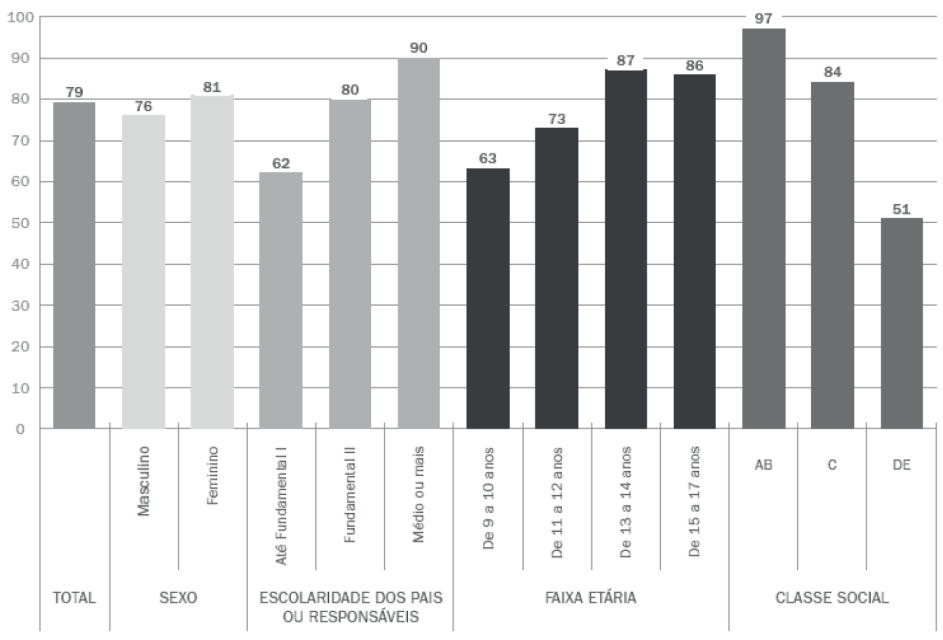

Fonte: CETIC.Br.

Estes dados ratificam que tanto no Brasil quanto fora dele, temos uma geração que interage intensamente com o universo digital e a escola? Bem, a escola continua alheia a tudo isso, inclusive criando proibiçóes que vetam o uso destes artefatos tecnológicos nos espaços escolares, pois embora os professores e o corpo técnico administrativo das escolas utilizem para se comunicar e trocar informaçóes muitas vezes de forma lúdica, não conseguem atribuir sentidos pedagógicos para estas tecnologias, sendo mais fácil proibir o uso e a presença destes aparatos tecnológicos nos cenários escolares.

Assim, como os docentes não conseguem entender a interação intensa dos seus alunos, os pais também não, inclusive aqueles que são pesquisadores da área.

É neste cenário que se inscreve este artigo que tem o objetivo de analisar as discussōes e angústia dos pais pesquisadores da área de cultura digital, por meio da mediação do WhatsApp. 
Estes sujeitos membros do Centro de Pesquisa e Desenvolvimento Comunidades Virtuais (CV) da Universidade do Estado da Bahia, que tem como um dos seus objetivos formar novos pesquisadores na área de cultura digital, fazem parte de um grupo no WhatsApp, criado em 28 de março de 2014 e com 58 participantes, sendo que 16 são mães de crianças e adolescentes na faixa etária de seis meses a 18 anos; e seis pais.

O grupo possui uma dinâmica muito intensa e especialmente nos dias 05/07/2016 e 14/11/2016 discutiu sobre como se sentem ao ter que estabelecer limites para a interaçáo dos seus filhos com o universo digital. A segunda discussão foi fomentada pela publicação do manual de Orientação da Sociedade Brasileira de Pediatria sobre a saúde de crianças e adolescentes na era digital, publicada no dia 01/10/16. É importante ressaltar que as questóes que tensionam o relacionamento pais, filhos e tecnologias nesse grupo são frequentes, considerando a especificidade das linhas de pesquisa vinculadas ao $\mathrm{CV}$.

Mas o debate limita-se ao pronunciamento de nove pais que participaram intensamente das discussóes, sendo que três deles são do sexo masculino. Os demais membros do grupo adotam a postura de voyers, acompanhando o que é dito, sem se pronunciar, apenas observando. Estes sujeitos têm participação ativa em outros temas que emergem no grupo.

Tomaremos estes discursos, considerando a intensidade das discussóes ocorridas nos dias indicados acima, como objeto deste capítulo, não apenas para evidenciar as angústias dos pais em torno do seu papel diante do desejo de interação frequente dos filhos com as tecnologias digitais, especialmente as redes sociais, softwares de comunicação instantânea, jogos, aplicativos entre outras interfaces, mas especialmente para analisá-las e apontar o What$s A p p$ como um espaço para reflexão e formação de professores e pesquisadores. 


\section{Pais, filhos, pesquisadores e tecnologias}

A nossa imersão no universo da cultura digital, seja como docentes, palestrantes e pesquisadores é marcada pela inquietação dos pais e professores que não sabem como devem se comportar frente à intensa interação dos seus filhos com o universo digital, sentindo-se muitas vezes impotentes para estabelecer os limites, especialmente porque são usuários dos dispositivos móveis e seus aplicativos e normalmente são confrontados pelos filhos quando restringem o uso.

Um uso que não é apenas de meros consumidores, mas de protagonistas, se autorizando a criar e compartilhar suas ideias e produçóes. Desta forma, compreendemos que a interação com estes dispositivos e aplicativos vai além de uma perspectiva instrumental, mas se constrói de forma inventiva e criativa (ALVES, 2016).

Nesse contexto emerge o aplicativo WhatsApp que já mobiliza adultos e crianças para atribuírem outro sentido aos aparelhos telefônicos. A propagabilidade discutida por Jenkins, Green e Ford (2014) ganha uma dimensão diferenciada, na medida em que os usuários, independente da faixa etária, socializam mensagens, notícias, vídeos, diferentes discursos, muitas vezes sem analisar sua veracidade.

Para os autores, a propagabilidade

reconhece a importância das conexóes sociais entre os indivíduos, conexóes cada vez mais visíveis (e amplificadas) pelas plataformas da mídia social. Essa abordagem pode ainda incluir mensuraçóes quantitativas de frequência e da amplitude dos deslocamentos de conteúdo, mas torna importante ouvir ativamente as maneiras pelas quais os textos de mídia são usados pela audiência e circulam por meio das interaçóes entre as pessoas. (JENKINS; GREEN; FORD, 2014, p. 29). 
É nessa direção que foi realizada a escuta sensível (BARBIER, 2002) dos pesquisadores e pais do CV, no grupo do Whats App durante as discussóes sobre até onde deve ir a proibição e limites do uso das tecnologias digitais por seus filhos. Para realizar a análise destas interaçóes textuais, foram selecionados os dias 05/07/16 e 14/11/16 conforme descrito anteriormente.

As telas do aplicativo foram printadas e posteriormente digitadas as falas em dois quadros, separando cada sujeito e dia da intervenção. Posteriormente, analisamos os dados produzidos e estabelecemos os aspectos para análise, considerando o que foi identificado.

$\mathrm{O}$ primeiro aspecto refere-se ao lugar que a tecnologia, especialmente os smartphones e tablets, ocupa na vida dos filhos dos sujeitos.

Os pesquisadores Gardner e Davis (2014) realizaram uma pesquisa analisando a interação dos jovens com os aplicativos, tomando como referência pessoas que nasceram no século XX e que nasceram no século seguinte. Para os autores, as pessoas têm sentimentos fortes sobre tecnologia e sua influência sobre os filhos, a sociedade e sobre si. Além disso, para Gardner e Davis existe um fascínio das pessoas em contemplar como a nova geração se difere das anteriores ${ }^{2}$.

$\mathrm{Na}$ pesquisa realizada, os aplicativos apareceram como uma das metáforas para os principais temas que emergiram durante a investigação. Para compreender essa metáfora, Gardner e Davis (2014) introduziram três conceitos-chave: aplicativo: mentalidade (app-mentality), habilitação (app-enabling) e dependência (app-dependence). O primeiro refere-se aos aplicativos utilizados para executar tarefas discretas, como a localização de um restaurante, comprar uma peça de roupa, ou falar com um amigo, a exemplo do

2 People hold strong feelings about technology and its influence on our children, our society, ourselves. Coupled with this is people's fascination in contemplating how the new generation differs from its predecessor (GARDNER; DAVIS, 2014, p. ix). 
WhatsApp, caracterizando-se como uma maneira algorítmica de pensar, perguntas e desejos que exigem satisfação definitiva e imediata.

Este tipo de aplicativo são caracterizados por ícones ou marcas que favorecem uma rápida identificação, evitando ambiguidades ou incertezas, como o carrinho de compras da Amazon, o pássaro do Twiter ou o balão com o fone de telefone do WhatsApp. Os pesquisadores registraram que estes tipos de aplicativos são utilizados pelos adolescentes, delineando seus perfis nas mídias sociais (2013, p. xii).

Gardner e Davis (2013, xiii) avançam distinguindo os app-habilitação e app-dependência:

Nós usamos aplicativos de habilitação para descrever situaçóes em que as pessoas usam seus dispositivos e aplicativos como trampolins para novas experiências e áreas de conhecimento, relacionamentos significativos e expressão criativa. Em contraste, o aplicativos de dependência surgem quando a tecnologia é usada como ponto de partida, ponto final e todo o resto - em outras palavras, quando os indivíduos olham para seus aplicativos e dispositivos antes de olhar para dentro de si mesmos ou chegarem a um amigo. ${ }^{3}$

A perspectiva apresentada pelos autores acima contribuiu para evidenciar na fala de todos os sujeitos escutados na nossa pesquisa que estes artefatos (os apps) se constituem em objeto de desejo para seus filhos, transitando entre os três conceitos apresentados, gerando preocupaçóes que passam por vários questionamentos que

3 We use app-enabling to describe situations in which youg people use their devices and apps as springboards to new experiences and areas of knowledge, meaningful relationships, and creative expression. In contrast, app-dependence arises when technology is used as a starting point, endpoint, and everything in between - in other words when individuals look to their apps and devices first before looking inside themselves or reaching out to a friend. 
serão indicados aqui, a exemplo de "Qual a idade certa para uma criança ter um celular (smartphone)?

Uma das mães - aqui denominada Raio de $\mathrm{Sol}^{4}$, deu o primeiro celular ao seu filho aos oito anos (seus filhos têm 6 , menina e 10 anos, menino). Já Zelda tem um filho de 6 anos que já tem celular e tablet e utiliza o primeiro para se comunicar com a máe e avó. Esta mãe sempre faz indicaçóes de textos, aplicativos e jogos no grupo, inclusive foi quem compartilhou o Manual de orientação que fomentou a discussão do dia 14/11/16.

Mestre Yoda, um dos pais do grupo, tem uma filha de 8 anos que interage com aplicativos, youtube, jogos e desde os três anos utiliza o smartphone do pai e aos 6 ganhou o seu, tendo inclusive Whats App. Segundo o pai, a filha desenvolveu um senso crítico que o surpreende muitas vezes.

Super Mário, outro pai de um menino de 6 anos, resolveu não limitar a interação do filho com as tecnologias.

Kratos, pai de dois filhos, um menino e uma menina, com idades de 12 e 14 respectivamente, chegou ao consenso com os filhos que só teriam aparelho celular a partir dos 10 anos.

É importante ressaltar que os três pais também interagem desde pequenos com os jogos digitais e são pesquisadores dessa área.

Em contraponto, duas mães com filhos com idades entre 2 a 9 anos decidiram esperar mais tempo para dá um celular aos filhos, pois consideram que eles ainda náo têm maturidade.

Virginiana deu o celular para seu filho de 14 anos, quando ele completou 13.

A pesquisa realizada pela Kaspersky, já citada anteriormente, aponta que

as razóes para essa crescente utilização dos smartphones refere-se ao fato de ser agora mais barato

4 Para preservar a identidade dos sujeitos, utilizaremos nomes fictícios criados apenas para este capítulo pelas autoras. 
com maior capacidade de armazenamento e com telas maiores e com mais funcionalidades, possibilitando realizar várias açóes. Mas acima de tudo são pequenos e portáteis permitindo que usuários de qualquer idade possa levar para qualquer lugar, tornando-o essencial para sua vida online, levando-os para todos os lugares. (GROWING..., 2016, p. 5). ${ }^{5}$

Para os pesquisadores, a condição generalizada do século 21 que é o medo de perder (em inglês FOMO - fear of missing out) se combina com a angústia e o desejo dos adolescentes de estar perto dos amigos em todos os momentos, tornou os smartphones irresistíveis, pois podem está all always conectados aos seus amigos (GROWING..., 2016, p. 5). ${ }^{6}$

O segundo aspecto pontuado pelos pais é a segurança, isto é, como garantir que as crianças e adolescentes estarão protegidos nas redes sociais, inclusive no WhatsApp, considerando que não se pode ser onipotente e onipresente, monitorando todos os conteúdos, acessos e conversas. As estratégias de controles variam para cada um dos sujeitos, ou seja, de não usar o WhatsApp no final de semana "para ter respaldo para mediar o tempo de uso no dispositivo móvel por parte dos filhos” (RAIO DE SOL).

5 Traduçâo livre das autoras "The reasons for this growing use include the fact that smartphones are now cheaper, with larger screens and memories and greater functionality - so they can do more. But, most of all they are small and portable and allow users of any age to carry their indispensable online life withthem wherever they go. The widespread, 21st century condition: FOMO ('fear of missing out'), combined with teenage angst and a natural desire to be close to one's friends at all times, make connected phones irresistible companions".

6 Traduçấo livre das autoras "The reasons for this growing use include the fact that smartphones are now cheaper, with larger screens and memories and greater functionality - so they can do more. But, most of all they are small and portable and allow users of any age to carry their indispensable online life withthem wherever they go. The widespread, 21st century condition: FOMO ('fear of missing out'), combined with teenage angst and a natural desire to be close to one's friends at all times, make connected phones irresistible companions". 
Yara declara que "a questão é a porta aberta da internet e a (in)maturidade da filha para passar por determinadas situaçóes".

Princesa registra que "não vê maldade no filho para saber separar as situaçóes. E que ela na sua infância foi muito aterrorizada pela mãe com recomendaçôes do tipo: não fale com estranhos, não aceite nada de ninguém...”.

A Safernet é uma organização não governamental preocupada com os direitos humanos e com a ética no ciberespaço, tem como um dos objetivos "transformar a Internet em um ambiente ético e responsável, que permita às crianças, jovens e adultos criarem, desenvolverem e ampliarem relaçóes sociais, conhecimentos e exercerem a plena cidadania com segurança e tranqüilidade"7. Esta ONG tem tido um papel importante em diferentes espaços, inclusive nos escolares e acadêmicos, discutindo e orientando crianças, adolescentes, pais e especialistas para o uso seguro da internet.

A discussão que ocorreu no dia 14/11/2016 sobre o manual de orientação para Saúde de crianças de adolescentes na era digital envolveu seis mães e dois pais. $\mathrm{O}$ referido documento tem o objetivo de orientar pais, professores e especialistas sobre o uso da tecnologia por parte de crianças e adolescentes sob o ponto de vista médico. Para os autores do documento "[...] tanto os pais como os educadores nas escolas precisam aprender como exercer esta mediação e serem alertados sobre os riscos e os limites necessários para assumirem esta responsabilidade" (MANUAL..., 2016, p. 2). Contudo, o referido documento só enfatiza os aspectos negativos, como dificuldades de socializaçáo e escolares, aumento da ansiedade, cyberbullying, problemas de alimentação e de sono, sedentarismo, dentre outros, chegando ao ponto de indicar uma "dieta midiática".

7 Disponível na URL: <http://www.safernet.org.br/site/institucional.> Acesso em: 14 jun. 2017. 
Diante do conteúdo do documento, os pais reagiram, buscando um ponto de equilíbrio para o que foi prescrito, já que era um tema que consideravam "um território de angústia e dúvidas" (KRATOS).

Yara questiona:

Como a autoridade médica prevalece sobre a autoridade familiar? Pais e mães precisam que alguém, no caso o médico, diga quanto tempo seu filho pode ficar na internet? Se a família não assume seu papel, algo fica fora de ordem, por que a autoridade médica é homogeneizante. O documento apresentado tem uma boa intenção. Não questiono o documento, que apresenta alguns equivocos no meu olhar de educadora, mas traz reflexóes importantes sobre esse fenômeno. O que questiono é justamente onde nós, família, e ai não só os pais e mäes, mas toda a família, está querendo para chegar ao ponto de delegar a outras pessoas, responsabilidades que são nossas?

A fala de Yara que se prolonga em um post seguido no WhatsApp aponta vários aspectos, inclusive, indicando referências, a exemplo de Bauman (2000) e McGonigal (2012) para respaldar suas ponderaçôes. No discurso acima, podemos constatar um ponto que vai se repetir na fala de outros pais, que se referem a responsabilidade do controle do tempo e uso, isto é, quem efetivamente decide? Devemos ouvir as crianças, mas os adultos é quem decidem? Outro ponto interessante refere-se ao fato de que não existe uma única forma, não existem prescriçóes médicas ou sociais únicas, não devemos homogeneizar, pois cada família irá decidir, considerando sua cultura, valores, entre outros aspectos fundantes na formação de novos sujeitos.

Para Princesa, o filho dela precisa ouvir um não:

às vezes ele tenta me testar... vai querendo atingir meu limite. O problema é que nós (ou pelo menos, muitos de nós) sabemos os limites de tempo para cada coisa e que se náo cumprirmos os prazos seremos punidos. Eles, enquanto criança, não possuem essa noçáo. Por isso, a importância do nosso papel de intervenção. Não existe fórmula mágica. Cada pai e mãe terá que dosar essa medida de acordo com a sua realidade. 
Zelda reforça as palavras de Princesa, sobre a importância do limite, ampliando para o adulto. "Infelizmente não podemos dedicar muito tempo aos nossos filhos. Vejo também que muitos adultos não conseguem administrar bem seu próprio tempo e limite".

Uma pesquisadora que não é mãe também enfatiza que "vivemos a internet de todas as coisas". Falamos das crianças. E nós, qual o limite? Quanto tempo ficamos sem olhar o zap?8

O controle inibitório é uma habilidade executiva fundamental no processo de desenvolvimento, pois nos prepara para viver na sociedade, respeitando o nosso limite e o limite do outro. Para Dias e Seabra (2013, p. 207):

A inibição é grandemente relevante em inúmeras tarefas e situaçóes do dia a dia, pois provê ao indivíduo o controle de seus processos cognitivos, emocionais e comportamentais, suplantando o controle por eventos externos, reaçóes emocionais automáticas, tendências prévias ou habituais. Dessa forma, o indivíduo se torna capaz de inibir impulsos, comportamentos inadequados, respostas automáticas ou prepotentes, assim como estímulos irrelevantes ou distratores, de modo que possa ponderar e pensar antes de emitir uma resposta.

O controle inibitório é uma das habilidades executivas, junto com a flexibilidade cognitiva e memória operacional fundamental para o desenvolvimento do sujeito e começa a ser construído a partir dos 12 meses de idade, atingindo seu ápice no final da adolescência e declínio na terceira idade. Assim, esse limite discutido pelos pais, no caso desse capítulo, em relação à interação com as tecnologias deve ser estimulado nos distintos espaços de aprendizagem nos quais os sujeitos estejam imersos a fim de que seja internalizado pelas crianças e adolescentes.

8 Os sujeitos da pesquisa utilizam as expressôes Zap e Wpp para se referir ao WhatsApp. 
Ainda em relação aos limites, os pais do grupo questionam o papel do estado, definindo o que pode ou não pode ser feito dentro das suas casas, mas defendem uma liberdade assistida junto às crianças, assim como a sistematização de recomendações.

Esses pequenos e significativos recortes das preocupaçóes dos pais em relação à interação dos filhos com as tecnologias, apesar de serem pesquisadores da área, sinalizam a importância de temos um fórum de debate contínuo, potencializando os espaços criados pelos grupos no WhatsApp para compreendê-lo como um âmbito de aprendizagem no qual se pode aprender com a escuta do outro, discutir e construir juntos uma trilha que contemple a diferença, a escuta sensível e valorize a interação e construção mediada pelas tecnologias sem posturas apocalípticas (ECO, 2015).

A análise das falas dos pais permitiu identificar pontos de tensionamento, como por exemplo: princípios que norteiam a educação dos filhos - entre a reproduçáo de modelos e a construção de práticas que respeitem a individualidade dos filhos.

As discussóes possibilitaram que mães como Princesa e Virginiana relembrassem suas infâncias:

Meninas lendo e pensando. Sabe.. quando eu era pequena minha mäe estabelecia limites... muitos... quanto tempo no quintal, jogando bola, baleado, fazendo comidinha...pois não poderíamos ficar o "tempo todo brincando"”. Eu morria de ansiedade pela hora em que ia brincar na praça com a galera. (VIRGINIANA).

Outro ponto refere-se às práticas de negociaçáo - cumprimento de rotinas que levam ao uso

Mario Bros declara que resolveu não limitar e não colocar regras para o uso da tecnologia. Contudo, "estabelece outras regras a exemplo de estudar e fazer outras atividades e essas regras acabam por estabelecer limites para a utilização das tecnologias. E eu não abro mão da fiscalização". 
O brincar na contemporaneidade foi outro ponto enfatizado pelos pais, inclusive, estabelecendo relação com as formas de brincar na infância deles.

Eu fico me perguntando por que resgatar brincadeiras antigas. Brincadeiras que só fazem sentido dentro do contexto cultural daquela geração. Eu fico realmente pensando e tentando näo ser preconceituosa. A escola de Mafalda (tem 9 anos) fez isso este ano. E eu perguntei: qual o objetivo? A escola me disse que era para resgatar a cultura dos pais e dos avós, por que hoje em dia as crianças não brincam mais como antigamente. Eu disse: é óbvio que não. Assim, como nós não brincamos como nossos avós. A gente sempre ressignifica o brincar... o viver.... eu não entendo por que essa nostalgia. Ai eu perguntei qual o problema com as brincadeiras de hoje em dia? A professora falou da tecnologia e que os pais sempre reclamam e pedem para a escola ajudar. Eu realmente entendi que estamos em uma transição. E não é fácil entender as novas lógicas de viver, de trabalhar, de brincar, assim como nossos avós e pais também não entenderam. (YARA).

Zelda que tem um filho de 6 anos em uma escola particular compartilha o seguinte depoimento: "Tenho observado que a escola de meu filho está organizando um movimento em oposição ao uso das tecnologias digitais, promovendo eventos falando do resgate de brincadeiras antigas e mandando alerta aos pais com o tema".

A fala de Yara e Zelda destaca pontos significativos e que emergem cotidianamente, seja no discurso da mídia, nos dos pais, dos professores e especialista, um saudosismo que visa desqualificar o momento atual, já que não consegue lidar com o novo (que não é tão novo assim).

Como Yara pontuou não é possível pensar no brincar sem atentar para as mudanças culturais, sociais, antropológicas, tecnológicas, por exemplo, que tensionam as relaçóes na sociedade contemporânea.

Outro ponto relevante é a transferência da família para que a escola resolva ou aja nas zonas de tensão nas quais os pais se sentem impotentes para tomar decisóes - a mediação e acompanhamento do acesso dos filhos ao universo tecnológico. 
E ainda o já táo discutido fosso geracional entre a escola professores e alunos. Tal fosso contribui para que a escola seja um lugar de desprazer no qual os docentes não estáo sendo formados para uma sociedade permeada por tecnologias que possibilitam que seus usuários sejam mais que consumidores.

Por que a escola resiste em dialogar com o seu entorno? Uma forma de se aproximar do contexto dos alunos é construindo práticas lúdicas, atentando para suas três dimensóes: reconhecer que o brincar e as atividades lúdicas de maneira geral são criaçôes culturais, produzidas nas relaçôes entre os homens no contexto social; compreender a ludicidade como um estado de ânimo e que se relaciona com a realidade interna do indivíduo; e pensar a ludicidade como princípio formativo que deve está presente no espaço escolar como elemento estruturante para produzir aprendizagens significativas (LEAL; D’ÁVILA, 2013).

Diariamente constatamos a inabilidade da escola lidar com as tecnologias outro aspecto evidenciado nas falas dos pais.

A escola do meu filho proibiu completamente o uso do celular nas dependências da escola. E nem mesmo às sextas (dia livre para levar o brinquedo que quiser) eles podem levar o tablet ou celular. Batman [filho de Princesa] já não levava mesmo porque ele tinha medo de perder ou quebrar. Mas particularmente fiquei arrasada com a iniciativa. Acho que a escola deve criar estratégias para o uso das tecnologias na escola e não proibir. (PRINCESA).

Magali, professora que ainda não é mãe e em diálogo com Princesa, diz: "o problema é que os professores (a grande maioria) não estão preparados para utilizar as tecnologias e por isso é melhor banir. Porque as crianças estáo a léguas de distância no uso".

Princesa ilustra um pouco mais sua relação com a professora de Batman, de uma escola particular, mediada pelo WhatsApp:

Mandei o wpp para a professora dele e recebi a resposta dois ou três dias depois (sabia que ela ia demorar para responder, pois tinha visto o dia da última 
visualização). Eles não estão preparados para o uso das tecnologias e da importância desses dispositivos em sala de aula.

E por onde anda o desejo dos professores? Yara registra ainda que:

Imagino como deve ser dificil a realidade dos professores e a sobrecarga. Mas quando digo que imagino é porque sabemos das dificuldades de incentivos do governo para facilitar o acesso aos dispositivos e a formaçáa dos professores, pois não adianta ter e não usar. Digo isso, porque as escolas particulares cobram uma fortuna dos pais e terminam agindo da mesma maneira que as escolas públicas.

Neto, Versuti e Vaz (2016) descrevem as pesquisas realizadas na Índia, Israel e no Brasil com a mediação do WhatsApp nos ambientes escolares e acadêmicos, apontando limites e possibilidades para compreender este aplicativo como um espaço de aprendizagem que vai além das possibilidades de comunicação (SANTOS; PEREIRA; MERCADO, 2016; KAIESKI; GRINGS; FETTER, 2015; BOUHNIK; DESHEN, 2014).

A importância das discussóes iniciadas no grupo do WhatsApp do CV ratifica a necessidade de ouvir crianças, adolescentes, pais e professores para que juntos possam encontrar caminhos para efetivar a interação dos seus filhos com as tecnologias de forma prazerosa e segura. O nível de reflexão e preocupação evidenciada aqui ratifica que para além de um espaço para comunicação livre para encontrar e falar com amigos e familiares, compartilhando distintas mídias e pontos de vista, o WhatsApp pode se constituir em um espaço formativo para os diferentes temas, interesses e grupos, ratificando a ideia de Lèvy (1998) da construção em tempo real, envolvendo pessoas que estáo em distintos pontos geográficos e com diversas perspectivas podem construir uma inteligência coletiva, centrada nos aforismas indicados pelo autor: ninguém sabe tudo, todo saber está disponível na humanidade e cada um tem um saber. E ainda para Giedd (2012, p. 3): 
Uma das habilidades mais úteis para crianças e adolescentes adquirirem será a habilidade de efetivamente utilizar este universo de informação - para criticamente avaliar os dados, para discernir sinais de barulhos, sintetizar conteúdos, e aplicar tudo isso à resolução de problemas no mundo real? .

Esse é o desafio de pais, educadores e especialistas, permitir que a geração que interage intensamente com as redes sociais e as tecnologias digitais e telemáticas possam: experimentar, construir sentidos e aprender com elas as questóes relacionadas com o uso, segurança e possibilidades de aprendizagem, mas com a interlocução e mediação do adulto, não como um censor, mas um parceiro nessa aventura.

\section{Consideraçóes finais - Encaminhamentos}

A discussão realizada pelos pais pesquisadores da cultura digital nos sinaliza pontos importantes que não podem ser preteridos. Inicialmente é pensar de qual lugar falamos das tecnologias. O que elas sáo e como lidamos com elas. Compreender as tecnologias digitais e telemáticas para além de ambientes determinantes de comportamentos positivos e negativos, mas como espaços de produção e criação nos quais adultos, crianças e adolescentes podem experimentar e criar novas formas de aprender, tendo liberdade para se expressar, interagir e compartilhar diferentes pontos de vista mediado por diferentes linguagens. Contudo, precisamos aprender a lidar com esse universo desterritorializado no qual devem existir limites não apenas de uso, mas de respeitar o outro para ser respeitado, para aprender a conviver com a diferença.

9 "One of the most useful skills for children and adolescents to acquire will be the ability to effectively utilize this universe of information - to critically evaluate the data, to discern signal from noise, to synthesize the content, and to apply it to real-world problem solving”. 
Quando se trata de crianças e adolescentes, o controle é fundamental, mas não de forma autoritária, mas negociado, favorecendo a criação de estratégias de interação e junto construir indicadores que emergem a partir de protocolos culturais, valores, interesses e desejos de cada núcleo familiar, rompendo com a ideia de patologizar o novo, o diferente, o que não conhecemos, mas aprender a interagir com o WhatsApp, por exemplo, para além das questóes comunicacionais, interagindo com os recursos existentes nesse aplicativo para evitar que se torne uma torre de Babel.

E em sintonia com Bouhnik e Deshen (2014, p. 230) concordamos que

se Whats $A p p$ torna-se uma ferramenta comum para professores e alunos em sala de aula, haverá necessidade de mais pesquisas para identificar as propriedades do usuário e a melhor maneira de integrá-lo sem metas educacionais e pedagógicas. Isso exigirá a implementaçáo de uma vasta gama de metodologia de pesquisa qualitativa. Essa pesquisa produzirá inevitavelmente conclusões teóricas e práticas. As entrevistas neste estudo [referem-se a pesquisa realizada em Israel e já indicada anteriormente] foram com estudantes do ensino médio; Pesquisas adicionais devem também envolver escolas de ensino fundamental e universidades. ${ }^{10}$

Assim, o WhatsApp pode se constituir em um espaço de formação e investigação para os docentes e pais discutirem e juntos construírem trilhas de interação seguras, criativas e ricas de sentidos.

10 If WhatsApp becomes a common tool for teachers and students in the classroom, there will be need for further research in order to identify user properties and the best way to integrate them into educational and pedagogical goals. This will necessitate the implementation of a wide range of qualitative research methodology. Such research will inevitably yield both theoretical and practical conclusions. The interviews in this study dealt with high school students; further research should examine junior high and elementary schools and universities as well. 


\section{Referências}

ALVES, Lynn. Práticas inventivas na interação com as tecnologias digitais e telemáticas: o caso do Gamebook Guardiōes da Floresta. Revista de Educaçáo Pública, v. 25, p. 574-593, 2016.

ABREU, Cristiano Nabuco de; EISENTEIN, Evelyn; ESTEFENON, Susana Graciela Bruno. Vivendo esse mundo digital - impactos na saúde, na educação e nos comportamentos sociais. Porto Alegre: ArtMed, 2013.

BARBIER, Rene. A pesquisa-ação. Tradução por Lucie Didio. Brasília: Plano, 2002. (Série Pesquisa em Educação, v.3).

BAUMAN, Zygmunt. Modernidade líquida. Rio de Janeiro: Zahar, 2000.

BOUHNIK, Dan.; DESHEN, Mor. WhatsApp goes to school: mobile instant messaging between teachers and students. Journal of Information Technology Education. Santa Rosa, v.13, p.217-231, 2014. Disponível em: <http://www.jite.org/ documents/Vol13/JITEv13ResearchP217-231Bouhnik0601. pdf>. Acesso em: 15 jun. 2017.

COMITÊ GESTOR DA INTERNET NO BRASIL - CGI.br. Pesquisa sobre o uso da internet por crianças e adolescentes no Brasil [livro eletrônico]: TIC Kids on-line Brasil 2015 / Núcleo de Informação e Coordenação do Ponto BR, [editor]. São Paulo: Comitê Gestor da Internet no Brasil, 2016.

DIAS, Natalia Martins; SEABRA, Alessandra Gotuzo. Funçóes executivas: desenvolvimento e intervenção. Temas sobre desenvolvimento. 2013; v. 19, n.107, p.206, 2012. Disponível em: 
<https://www.researchgate.net/publication/281177320_funcoes_ executivas_desenvolvimento_e_intervencao>. Acesso em: 9 jun. 2017.

ECO, Umberto. Apocalípticos e integrados. São Paulo: Perspectiva, 2015.

GARDNER, Howard; DAVIS, Katie. The app generation. Yale University Press: New Haven and London, 2014.

GIEDD, Jay, N. The digital revolution and adolescent brain evolution. J. Adoles Health, v. 51, n. 2, p. 101-105, 2012.

GROWING UP ONLINE. What Kids. Conceal. Kaspersky Lab, abr. 2016. Disponível em: <https://kids.kaspersky.com/ wp-content/uploads/2016/04/KL_Report_GUO_What_Kids_ Conceal.pdf>. Acesso em: 14 jun. 2017

INTEL SECURITY TEENS, Tweens and Technology Study India. Intel Security. 10/07/2015. Disponível em: <http://apac. intelsecurity.com/digitalsafety/wp-content/uploads/sites/7/2015/10/ Intel-Security_India-Teens'Tweens'Technology-2015-_NationalDatasheet.pdf >. Acesso em 15 jun. 2017.

JASON. Sabe quantos usuários têm WhatsApp em 2017? Como escolher. 2017. Disponível em: <http://www.howtochoosealaptop. com/pt/do-you-know-how-many-users-have-WhatsAppon-2017/>. Acesso em: 1 abr. 2017

JENKINS, Henry; GREEN, Joshua; FORD, Sam. Cultura da conexáo - criando valor e significado por meio da mídia propagável. São Paulo: Aleph, 2014. 
KAIESKI, Naira; GRINGS, Jacques André; FETTER, Shirlei Alexandra. Um estudo sobre as possibilidades pedagógicas de utilização do WhatsApp. Revista Renote: Novas tecnologias na Educação, Porto Alegre, v.13, n.2, p.1-10, 2015. Disponível em: <http://seer.ufrgs.br/index.php/renote/article/view/61411>. Acesso em: 15 jun. 2017.

LEAL, Luiz Antonio Batista; D’ÁVILA, Cristina Maria. A ludicidade como princípio formativo. Interfaces Científicas Educação, Aracaju, v. 1, n. 2, p. 41-52, fev. 2013.

LÈVY, Pierre. A inteligência coletiva - para uma antropologia do ciberespaço. São Paulo: Cortez, 1998.

MANUAL de Orientação. Saúde de crianças e adolescentes na era digital. Departamento de Adolescência. Sociedade Brasileira de Pediatria. 01/10/2016. Disponível em: < http://www.sbp.com. $\mathrm{br} /$ fileadmin/user_upload/2016/11/19166d-MOrient-SaudeCrian-e-Adolesc.pdf>. Acesso em: 1 abr. 2017.

McGONIGAL, Jane. A realidade em jogo - por que os games nos tornam melhores e como eles podem mudar o mundo. Rio de Janeiro: Best Seller, 2012.

NETO, Antônio Oliveira; VERSUTI, Andrea; VAZ, Wesley, F. Perspectivas para o uso do WhatsApp Messenger no estímulo à aprendizagem dos sujeitos. In: COUTO, Edvaldo; PORTO, Cristiane; SANTOS, Edméa (Org.). App-learning - experiências de pesquisa e formaçáo. Salvador: EDUFBA, 2016. p. 227-244.

SANTOS, Vera Lúcia Pontes; PEREIRA, Jasete Maria Santos; MERCADO, Luís Paulo Leopoldo. WhatsApp: um viés online como estratégia didática na formação profissional de docentes. 
ETD: Educação Temática Digital, Campinas, SP, v.18, n.1, p.104121, 2016. Disponível em: <https://periodicos.sbu.unicamp.br/ojs/ index.php/etd/article/view/8637398>. Acesso em: 15 jun. 2017.

SIMPLES. Seguro. Troque mensagens com confiança. WhatsApp. 2017. Disponível em: <https://www. WhatsApp.com/?l=pt_br>. Acesso em: 1 abr. 2017. 